\title{
Programas de vivienda social nueva y mercados de suelo urbano en el Perú ${ }^{1}$
}

Julio Calderón. Consultor independiente, Lima, Perú. ${ }^{2}$

Resumen | El gobierno del Perú está implementando el Programa Techo Propio Adquisición de Vivienda Nueva (AVN), destinado a los sectores de menores ingresos. El logro de su objetivo, sin embargo, se ha visto obstaculizado por diversos problemas, como el desbalance existente entre la demanda, por una parte, y los escasos proyectos de vivienda desarrollados en el país y precios de la tierra urbana, por otra. Para el estudio de esta situación se realizaron dos tipos de análisis, cualitativo y cuantitativo, destinados a evaluar los resultados del programa. Junto con la revisión de la literatura sobre el tema, la herramienta utilizada para dichos análisis fue el estudio de casos (Lima y Trujillo), con la aplicación de una encuesta y el desarrollo de entrevistas, en un enfoque en que se examina la situación del Perú en perspectiva comparada con otros países de América Latina.

PALABRAS ClAVE | política habitacional, mercado inmobiliario, mercado de suelo.

ABSTRACT | The Peruvian government is implementing a housing program (Programa Techo Propio Adquisición de Vivienda Nueva [AVN]) aimed at low income sectors. However, this program has encountered several problems during its implementation, mainly in the form of a significant imbalance between housing demand on the one hand, and the low number of housing projects that have taken place in the country, coupled with the price of urban land, on the other. This paper presents an approach to this situation based on qualitative and quantitative analyses, aimed at evaluating the results of the program. Together with a literature review of pertinent research on the subject, research was carried out on two case studies (the cases of Lima and Trujillo), through the application of a survey and in-depth interviews, using a comparative perspective in order to relate the Peruvian situation with other Latin American countries

KEYWORDS | housing policy, real estate market, land market.

Recibido el 29 de mayo de 2013, aprobado el 6 de noviembre de 2013

E-mail: calderon@chavin.rcp.net.pe

Correspondencia: Prolongación Arenales 773, departamento 402, Miraflores, Lima, Perú.

1 Este artículo es una versión abreviada del estudio "Política de Vivienda Social y mercado de suelo urbano en el Perú”, financiado por el Lincoln Institute of Land Policy, de Estados Unidos de América. Agradezco a Martim Smolka, Francisco Sabatini y Anna Sant'Anna por su lectura y observaciones; y a Rodolfo Santa María, por su apoyo. Rocío Morales, Álvaro Calderón, Teresa Arias, Olga Sihuacollo y Michael Elorreaga participaron como encuestadores. Asimismo, agradezco a los dirigentes de los conjuntos habitacionales por autorizar la aplicación de la encuesta.

2 Con la colaboración de Jesús Quispe. Economista, director del Instituto de Desarrollo Urbano CENCA, Lima, Perú 


\section{Introducción}

La política de vivienda social en el Perú se materializa por medio de dos programas: Nuevo Crédito Mi Vivienda y Techo Propio. Con tales instrumentos, el Estado peruano busca enfrentar el déficit de vivienda que, según el censo de 2007, fue estimado en 1.860.692 unidades, de las que unas 1.470.947 (79\%) corresponden al déficit cualitativo y unas 389.745 (21\%) al déficit cuantitativo. Tal distribución implica que el grueso del déficit de vivienda afecta a aquellas unidades habitacionales que, surgidas de invasiones de tierras o compras ilegales, se ubican en los asentamientos de sectores de menores ingresos.

El Programa Nuevo Crédito Mi Vivienda está dirigido a la clase media y consiste en unidades nuevas (Calderón, 2009). El Programa Techo Propio, orientado a los sectores de menores ingresos, tiene tres modalidades, dos de ellas conducentes a atender el déficit cualitativo de vivienda, que se denominan Construcción en Sitio Propio y Mejoramiento de Vivienda (Calderón 2012b). Una tercera modalidad, Adquisición de Vivienda Nueva (AVN), está destinada, como su nombre lo indica, a atender la demanda cuantitativa de vivienda. Este artículo aborda el estudio de esta tercera modalidad, el Programa Techo Propio en su modalidad de Vivienda Nueva, dirigido a los sectores de menores ingresos.

Los diversos estudios sobre la producción de vivienda social en América Latina coinciden en que la elevación de los precios en el mercado del suelo representa un duro escollo para la aplicación de las políticas habitacionales. Este argumento -reiterado, aunque con matices- goza de aceptación entre académicos, funcionarios de entidades gubernamentales y empresarios de la construcción. Para someter a prueba tal hipótesis, se tomó como estudio de caso el Perú y, particularmente, al programa público Techo Propio Adquisición de Vivienda Nueva (AVN), implementado desde 2002, que promueve un mercado de vivienda subsidiada para los sectores de menores ingresos.

La política de vivienda social o vivienda de interés social (vIs), términos que usaremos como equivalentes a efectos de este trabajo, y que refiere en esencia a una vivienda dirigida a los sectores sociales que por sí solos no pueden adquirirla en el mercado, expresa -en el nivel histórico y teórico- las dificultades de los mercados formales privados y públicos para proveer viviendas a una buena porción de la población urbana. Los intereses de los agentes privados (constructores, promotores, bancos, comerciantes, propietarios de la tierra, etcétera) en el negocio inmobiliario terminan por valorizar la vivienda por encima de la capacidad de pago de un buen número de población. La política de vivienda social, que se basa en los subsidios directos al consumidor, asume que el Estado debe proporcionar a los hogares insolventes dinero -en efectivo y en crédito hipotecario- para completar su capacidad de pago, de modo que puedan cubrir la diferencia entre lo que sus reducidos ingresos les permiten cubrir, y una vivienda con un valor tope establecido.

La teoría social y urbana ha mostrado que, en la industria de la construcción, los elevados costos de producción, la importante inversión inicial, el alto precio del suelo y la lenta rotación de capital se encuentran tras el llamado "problema de la vivienda"

y también tras la necesidad de subsidios para compensar los desequilibrios entre la 
oferta y la demanda (Cortés, 1995; Pradilla, 1982). Los subsidios contradicen la interpretación de una armoniosa autorregulación que, a partir de diversos supuestos (como que la producción de bienes y servicios refleja la preferencia de los consumidores, que todas las familias y firmas tienen perfecta información, que las familias maximizan utilidades y la producción es flexible...), provee vivienda (Basset \& Short, 1980, p. 26). En cuanto al mercado de suelo urbano, desde la economía se afirma que las externalidades de la ciudad no proporcionan un uso óptimo del suelo y hay falta de mercado para muchos bienes y servicios urbanos (Richardson, 1975, pp. 15-18).

El presente estudio se ubica en el meollo de la actual discusión urbanística en América Latina, caracterizada por los esfuerzos por aumentar el stock de vivienda social y, a la vez, reducir la informalidad en las ciudades. Por ejemplo, en Colombia, la legislación de reforma urbana, cuya elaboración y adopción significaron un largo proceso de algo más de cuatro décadas, tuvo como finalidad servir de soporte a las políticas de vivienda de interés social, y a sus propósitos de minimizar las ocupaciones informales y asegurar el acceso al suelo urbanizado, a la vivienda y a la integración urbana de las personas (Maldonado, 2012, p. 161). Un discurso similar fue el que se asumió en el Perú. La situación que recoge este estudio debe ser considerada un momento particular de lo que en general está sucediendo en América Latina.

En el marco del estudio se han revisado investigaciones latinoamericanas y peruanas en torno al tema, así como la información pública y de las páginas inmobiliarias de los diarios más importantes respecto del costo de suelo urbano, y se han realizado visitas de campo a algunos emprendimientos. La interpretación se propone en el nivel nacional y, con el ánimo de profundizar aspectos de análisis, se consideraron dos estudios de casos -Lima Metropolitana y Trujillo, primera y tercera ciudad del Perú-, con procesos de expansión y consolidación urbana parecidos y caracterizados por la enorme presencia de la ciudad informal.

La metodología del estudio básicamente se fundamenta en entrevistas a desarrolladores, constructores, funcionarios públicos y beneficiarios de la política. Junto a ello, se ha aplicado una encuesta -sobre una muestra estadísticamente representativa- a la población beneficiaria de unidades habitacionales en Lima (Martinete, Campoy, Santa Rita y Parques de El Agustino).

\section{Determinación del tamaño muestral}

Entre 2006 y 2011 en Lima se desembolsaron 2.776 Bonos Familiares Habitacionales para la construcción de viviendas nuevas, que representa el total de población, según el Ministerio de Vivienda (http://www.vivienda.gob.pe/Destacados/estadistica/10. mht) revisado el 6/8/11.

\section{Parámetros:}

\begin{tabular}{|l|l|l|l|}
\hline N & Total de población & 2.776 & \\
\hline z sub alfa & Seguridad 97,5\% & $97,5 \%$ & 2,24 \\
\hline p & Proporción esperada 5\% & 0,05 & \\
\hline q & $1-p$ & 0,95 & \\
\hline d & precisión 3\% & 0,03 & \\
\hline
\end{tabular}


Fórmula:

$$
n=\frac{N * Z_{z}^{2} p^{*} q}{d^{2} *(N-1)+Z_{z}^{2} * p^{*} q}=\frac{661,62074}{2,735836}=242
$$

El estudio consta de las siguientes partes. En primer lugar, se presentan algunas consideraciones teóricas económicas y políticas sobre la vivienda social y el problema del suelo. La siguiente sección presenta la situación actual de la economía y el mercado de vivienda en Perú, clave para contextualizar el análisis de la vivienda social. La tercera parte aborda los resultados del Programa Techo Propio Adquisición de Vivienda Nueva, considerando el desarrollo y localización de las soluciones habitacionales, las estrategias de rentabilidad de los constructores y promotores (modelo de negocio), los aspectos financieros y la intervención pública, incluyendo notas sobre algunos problemas detectados. Finalmente se entregan algunas reflexiones finales y la bibliografía.

\section{Vivienda social y problema del suelo}

En América Latina, la vivienda de interés social -o vivienda social, simplementeexperimenta un segundo aire tras su experiencia fallida entre las décadas de 1940 y 1960. No existe duda alguna respecto de que ha sido el impresionante éxito constructor en Chile, el que en 1996 llegó a producir unas 150.000 viviendas (Sugranyes, 2006, pp. 41 y 53), el que ha animado esta experiencia. En el marco del criterio institucional de intervención del Estado, se aplicó el principio de subsidiariedad - por medio de un subsidio a la demanda materializado en la entrega de bonos-, articulándose el capital constructor y el capital financiero y encargándose al sector privado el diseño de las propuestas y las soluciones habitacionales (Sugranyes, 2006, p. 28). El "modelo" fue luego seguido por México, Colombia, Costa Rica y el Perú, a partir de 2002.

Para entender mejor el análisis del segundo aire de la vivienda social, es necesario reflexionar sobre la primera experiencia en la materia. Entre 1940 y 1960, el Estado ubicaba y adquiría terrenos, diseñaba los programas y contrataba a la empresa privada para que ejecutara los conjuntos habitacionales al servicio de trabajadores que no podían acceder al mercado inmobiliario. Una de sus variantes era el sistema mutual, un "subsidio a la oferta" otorgado por el Estado, en el cual la iniciativa corría a cargo de las urbanizadoras. La experiencia fue fallida, y no resultó sostenible una vez que los fondos públicos, en el marco de diversas crisis, empezaron a escasear. La experiencia se abandonó y las políticas se orientaron a apoyar la regularización de la ciudad informal mediante programas de titulación, mejoramiento de vivienda y provisión de servicios, entre otros.

El fracaso de la primera experiencia se produjo porque las viviendas construidas se encontraban a precios fuera del alcance del sector de menores ingresos, terminándose por favorecer a la clase media, la cual no requeriría tanto del apoyo público. Los factores que explicaron precios de viviendas supuestamente sociales fuera del 
alcance del público al que iban dirigidas fueron diversos: los altos costos de construcción, la reticencia de la banca privada, la mala gestión estatal y las pérdidas económicas en la administración. Pero, sobre todo, estuvo la elevación del precio del suelo y el aprovechamiento de las rentas por parte de los propietarios. Resulta expresivo que el incremento y alto costo del suelo fueran el argumento por el cual se dio inicio a las políticas de vivienda social hacia la mitad del siglo XX, y que ese mismo argumento resultara explicando su fracaso.

El segundo aire de las políticas sociales de vivienda se ha dado en torno a los intentos por resolver varios problemas a la vez. El esfuerzo más importante, que atañe a la estructura urbana de la ciudad latinoamericana, está orientado a combatir la informalidad en el uso del suelo por medio de la promoción de alternativas formales, las que deberían acompañar el crecimiento económico. En este sentido, se postula para la vivienda social un carácter preventivo, en el sentido de que, bien encaminada, constituye una alternativa a la ciudad informal y, a la larga, disminuiría la secuela de programas de regularización (titulación) y mejoramiento, en esencia curativos. Junto a esos objetivos sociales, y en consonancia con los postulados liberales que orientan el manejo del Estado, la política busca promover la inversión privada, a bajo riesgo y con subsidios, en la construcción de vivienda social.

A pesar del entusiasmo con que se llevan a cabo las políticas de vivienda social, así como sus indiscutibles logros, las actuales experiencias en América Latina también muestran limitaciones. La limitación central es, al igual que antes, el incremento del precio del suelo urbano. Se ha sostenido, como en el caso de Santiago de Chile, que los subsidios a la vivienda social incrementan los precios de la tierra (Brian \& Sabatini, 2006), a diferencia de la creencia convencional entre los políticos que apoyan estas medidas, quienes piensan que los van a reducir (Landaure, 2010, p. 10). Los mayores precios del suelo presionan a los constructores a disminuir superficies y calidades, y a localizar los proyectos en las áreas más periféricas. Ello explicaría las críticas a la vivienda social chilena en términos de calidad y localización lejana (en tanto las áreas más próximas al centro se destinan a otros sectores socioeconómicos), problemas de integración a la trama urbana, falta de criterios de vivienda progresiva y de mecanismos de integración social, todo lo cual termina por generar nuevos conflictos, segregación social y guetos (Stockins, 2004, p. 93; Rodríguez \& Sugranyes, 2009; Segovia, 2006; Hidalgo, 2007).

Existen algunas consideraciones teóricas de base para entender la cuestión del suelo urbano. Diversos estudios empíricos han mostrado la especificidad del mercado del suelo, en el cual el aumento de la oferta no implica necesariamente una baja de los precios y la disminución de la demanda tampoco los hace descender (Topalov, 1984, pp. 6-8). El suelo es irreproducible, escapa de los supuestos de la competencia perfecta de la economía neoclásica, es objeto de una demanda especulativa que distorsiona el mercado, enfrenta externalidades positivas y negativas que generan divergencia entre costos/beneficios sociales y privados (Trivelli, 1994), entre otros aspectos necesarios de tener en cuenta.

El "problema del suelo" no puede reducirse a sus aspectos económicos. La gestión urbana, que regula las conexiones entre políticas de vivienda, suelo, propiedad y tributación, es un asunto capital (Calderón, 2006). Una de sus manifestaciones 
más visibles es el clásico debate entre planificación y mercado libre de suelo, o entre regularización o flexibilidad frente a los propietarios de tierras. En Chile, los economistas neoclásicos, con influencia en la esfera del poder, sostenían que el incremento de los precios obedecía a la escasez de suelo y que con el aumento de la oferta, por medio de la expansión de los límites urbanos, se reducirían los precios. Sin embargo, aplicadas las medidas, los precios del suelo no bajaron, sino que se elevaron continuamente (Trivelli, 2009, pp. 223-226; 2012)3. Hacia la década de 1990, el valor del suelo aumentó al punto de no soportar los valores nominales adjudicados a la vivienda social, las empresas desertaron de las licitaciones que exigían aporte del terreno y se aumentó el valor de la oferta de vivienda social, al riesgo de desfocalizarse de la población a la que se suponía debía atender (Sugranyes, 2006, pp. 53-54; Rodríguez \& Sugranyes, 2009, p. 62).

Este fenómeno muestra una desconexión entre los propósitos de una política pública de vivienda social y el comportamiento del mercado de suelo. Se ha intentado resolver esta desconexión, recurrente en la región, por medio de la intervención pública, sujeta al péndulo entre políticas inclinadas a la defensa irrestricta de la propiedad privada, y otras más bien dispuestas a aplicar cargas y beneficios a la propiedad y desarrollar mecanismos de captura de plusvalía urbana. Entre las diversas alternativas se han desplegado instrumentos como los "bancos de tierras", ajustes de tierras, la promoción de programas "mixtos" de vivienda para clase media y sectores de menores ingresos. Según las particularidades de cada país, estos instrumentos han sido aceptados (aunque aplicados con dificultad) o rechazados. Mientras que Colombia es un ejemplo de lo primero, Chile y Perú lo son de lo segundo.

La profundización del nexo entre vivienda social y mercado de suelo requiere considerar las particularidades históricas de cada formación social y la configuración estructural de los agentes como un paso a una teorización más acotada. En el caso de Santiago de Chile, la gran edificación de la vivienda social se produjo previa adquisición por los constructores de grandes pańos de tierra en la periferia durante la crisis de la década de 1980 (Sugranyes, 2006). Luego, sobre esos terrenos, los constructores hicieron vivienda social y, posteriormente, dejaron de hacerla cuando la renta de la tierra, que ellos controlaban, se acomodaba mejor a vivienda para otros sectores sociales. Este fenómeno fue acompañado del predominio del "sistema de promoción inmobiliario" (SPI), en el cual se integró al promotor inmobiliario con el capital financiero (Sabatini, 1990, p. 64). La integración de las diversas actividades (diseño, adquisición de suelo, urbanización, construcción, financiamiento, etcétera) tuvo como motivación el intento por controlar las rentas, disputándolas a los propietarios de la tierra, lo que llevó a convertir los precios del suelo no en un componente del costo de la vivienda, como usualmente se piensa, sino en parte de las ganancias generadas por los proyectos inmobiliarios: una renta capitalizada.

Detengámonos en los elementos clave de esta reflexión para aplicarlos al análisis del caso peruano. La integración de las diversas actividades de la edificación de 
viviendas en manos corporativas inmobiliarias y financieras - de ser correcta la apreciación de Sabatini (1990) - se habría producido en Chile superando etapas históricas en que prevaleció la acción de loteadores, sector público y empresas constructoras. Pero es evidente que este proceso requiere un nivel de desarrollo de fuerzas productivas, articulación y manejo empresarial que no necesariamente están presentes en todo lugar. En Perú este proceso no ha tenido lugar aún, aunque podría encontrarse "en ciernes", y los diversos agentes disputan ganancias y rentas en la producción de la vivienda. En Perú tampoco se han adquirido grandes paños de tierra en épocas de crisis. La estructura de la tenencia de la propiedad del área de expansión urbana, producto de la reforma agraria (1968-1975), arrojaba hacia 1994 en Lima, un promedio de 1,7 hectáreas por agricultor (Calderón, 2006). Entre los propietarios agrícolas de las áreas de expansión de las ciudades peruanas no hay propietarios capitalistas de suelo, sino pequeños parceleros que observan un comportamiento patrimonial y especulativo, actúan por su cuenta y no tienen apremio para vender.

En su dimensión institucional y legal, el comportamiento patrimonial de los propietarios de tierra es reforzado por un marco jurídico que es de defensa irrestricta de la propiedad privada. En el Perú, la Constitución de 1993, que eliminó el derecho a la vivienda, y el marco jurídico subsecuente (Ley General de Expropiaciones, decreto legislativo 313 y modificación del Código Civil) plantean dificultades para el establecimiento de medidas como cargas y beneficios a la propiedad, disposiciones antiespeculativas y mecanismos de recuperación de plusvalía urbana. En Colombia, por el contrario, desde principios de 1990 se han adoptado instrumentos de gestión del suelo, como porcentajes destinados a la vivienda social, el banco de tierras y gestión asociada, vinculada a la distribución equitativa de cargas y beneficios (Maldonado, 2012).

A partir de las distintas situaciones señaladas, el análisis de la problemática de la vivienda social y el mercado de suelo urbano en el Perú debe considerar agentes económicos claramente distinguibles entre constructores y propietarios de tierras, y un marco jurídico de defensa irrestricta del derecho de propiedad, lo cual explica las trabas al desarrollo de la vivienda social y la propia manera en que los agentes económicos conciben la solución a estos problemas.

\section{Economía y mercado de vivienda en el Perú}

En el Perú de los últimos diez años se asiste a una mejora de la economía, que ha ido acompañada de un proceso de diferenciación social y reducción de la pobreza. El índice del Producto Bruto Interno (РвI) aumentó en la década de 1990 a un acumulado de 47,6\% (tasa anual del 4\%) y, en la primera década del siglo xxi, a 73,6\% (tasa anual de 5,7\%) (Egúsquiza Economistas, desarrollo peruano.blogspot. com). La demanda interna creció en 2010 a 12,8\%, el registro más alto en dieciséis ańos. El ingreso per cápita por habitante llegó a us\$ 5.225, superando en 64\% al de hacía cinco años, duplicando el nivel de hace diez años, y ubicando al Perú como un país de ingresos medios. La pobreza, según el Instituto Nacional de Estadística 
e Informática (INEI), pasó del 58,5\% en 2006 a un 30,8\% en 2010. Unos 5,7 millones de peruanos dejaron la pobreza (http://Peru21.pe).

El crecimiento económico se ha articulado, desde el año 2002, con una política de vivienda que ha aplicado subsidios, generando menores tasas de interés (aunque también por la mayor competencia en el mercado) e iniciativas de fomento implementados por el Estado, como el Programa Techo Propio y el Fondo Mivivienda ${ }^{4}$ (Cámara Peruana de la Construcción [CAPECo], 2011, p. 8). A partir de 2006 se asiste al llamado boom inmobiliario, siendo que al 2010 la construcción ha retornado a las tasas de crecimiento que venía mostrando en los ańos precrisis financiera (2008-2009): un 17,4\%, nivel que no se observaba desde 1995.

La problemática de la vivienda social requiere ser comprendida dentro de los diversos submercados inmobiliarios que operan -formales/informales, privados/ públicos-, los que constituyen la demanda del mercado de suelo. En los mercados inmobiliarios formales privados se han producido verdaderas transformaciones, incorporándose la venta de vivienda construida a los tradicionales loteos urbanos. Continúan los mercados ilegales de tierras y existe un mercado de alquileres (legal e informal). Han surgido, de manera incipiente, grupos económicos que fusionan el capital constructor y el financiero.

La contribución del Estado a la activación del mercado de vivienda ha sido sustancial, bajo el principio facilitador que delega el diseńo y la ejecución al sector privado. El programa público más exitoso (hoy llamado Nuevo Crédito Mivivienda) ha sido el dirigido a la clase media y, desde su constitución, ha otorgado unos 68.000 créditos hipotecarios. El Programa Techo Propio, creado en septiembre de 2002, promueve la vivienda de interés social para los sectores de menores ingresos o "sectores populares" El programa, como se ha indicado, desarrolla tres modalidades: Construcción en Sitio Propio y Mejoramiento de Vivienda para quienes ya tienen terreno titulado y servido y desean remodelar, rehabilitar, culminar o ampliar su vivienda (Calderón, 2012b); y Adquisición de Vivienda Nueva, un subsidio dirigido a quienes no cuentan con terreno ni vivienda y que desean adquirir vivienda de primera venta, y que es el objeto de este estudio. Este programa promueve una vivienda con características mínimas (núcleo básico con ambiente multiuso, área para cocina y baño completo), cuyo valor no exceda las 12 o 14 Unidades Impositivas Tributarias (una UIT, aproximadamente 3.650 soles o us\$1.425).

Al Fondo Mivivienda corresponde la entrega del Bono Familiar Habitacional (вғH), complemento al ahorro de los grupos familiares beneficiarios del Programa Techo Propio, y que es traspasado directamente al promotor o entidad técnica para la ejecución de las obras. (Información en http:// www.mivivienda.com.pe/portalweb/promotores-constructores/pagina.aspx?idpage=81).

5 La ley indica que Techo Propio debe "promover la participación efectiva del sector privado en la construcción masiva de viviendas de interés social y a la vez facilitar mecanismos que permitan el acceso de los sectores populares a una vivienda digna” ("Crean el proyecto 'Techo Propio' Resolución Ministerial No 054-2002-Vivienda”, en http://geo.vivienda.gob.pe/dnv/documentos/ PTP/RM_054_2002.pdf). 


\section{Resultados del Programa Techo Propio, modalidad Adquisición de Vivienda Nueva}

\section{Desarrollo y localización}

La modalidad Adquisición de Vivienda Nueva no ha tenido el desarrollo esperado por las autoridades. De una hipotética entrega de 100.000 bonos en sus diez ańos de existencia, a noviembre de 2012 se han entregado 30.591 bonos (30,5\%). A diferencia, Nuevo Crédito Mivivienda (NCMv) para la clase media ha otorgado 67.617 créditos; y el de Construcción en Sitio Propio (CSP), unos 62.456 bonos. En cuanto al monto de la inversión pública, entre enero de 2006 y junio de 2012 se ha invertido aproximadamente us\$1.060.559.876 para la clase media, a un monto per cápita de us\$ 30.187; y us\$133.998.968 para Adquisición de Vivienda Nueva, a un monto per cápita de us\$5.732. La vivienda nueva para la clase media ha recibido del Estado un monto unas ocho veces mayor en términos absolutos.

CUADro I | Otorgamiento de créditos por modalidades del Programa Techo Propio y Bono Familiar Habitacional, 1999-2012

\begin{tabular}{|r|r|r|r|r|r|}
\hline AÑ̃S & NCMV & AVN & CSP & MV & TOTAL \\
\hline 1999 & 143 & & & & 143 \\
\hline 2000 & 405 & & & & 405 \\
\hline 2001 & 1.442 & & & & 1.442 \\
\hline 2002 & 3.611 & & & & 3.611 \\
\hline 2003 & 6.166 & 3.709 & & & 9.875 \\
\hline 2004 & 7.960 & 1.992 & 32 & & 9.979 \\
\hline 2005 & 9.205 & 702 & 15 & 9.939 \\
\hline 2006 & 5.540 & 625 & 762 & 163 & 6.189 \\
\hline 2007 & 3.123 & 2.262 & 10.029 & 922 & 16.022 \\
\hline 2008 & 2.994 & 2.077 & 22.807 & 1.753 & 32.172 \\
\hline 2009 & 3.527 & 4.085 & 12.807 & 543 & 2.4930 \\
\hline 2010 & 6.436 & 5.144 & 6.062 & 388 & 21.352 \\
\hline 2011 & 8.888 & 6.014 & 9.911 & 403 & 22.472 \\
\hline 2012 & 8.177 & 3.981 & 62.456 & 4.181 & 164.845 \\
\hline Total & 67.617 & 30.591 & & & 9 \\
\hline
\end{tabular}

NCMV = NUEVO CRÉDITO MI VIVIENDA; AVN = ADQUISICIÓN DE VIVIENDA NUEVA;

CSP = CONSTRUCCIÓN EN SITIO PROPIO; MV = MEJORAMIENTO DE VIVIENDA.

FUENTE MINISTERIO DE VIVIENDA, CONSTRUCCIÓN Y SANEAMIENTO (MVCS), HTTP://WWW.MIVIVIENDA. COM.PE/PORTALWEB/

En una primera etapa de la modalidad Adquisición de Vivienda Nueva, entre 2002 y 2006 (gobierno de Alejandro Toledo), se otorgaron solo 7.028 bonos y hubo reticencia de las grandes empresas constructoras a participar. Solo al primer año (2003) se esperaba construir unas 15.000 viviendas de un valor de us\$ 4.000 (Eyzaguirre \& Calderón, 2003, p. 41). Ante la falta de entusiasmo empresarial, tuvo que ser el propio gobierno el que habilitara las viviendas, recurriendo a la tierra pública y a la gestión financiera del Banco de Materiales. Solo pequeñas inmobiliarias se animaron a participar, algunas quebraron y otras tuvieron poca rentabilidad. 
La explicación oficial atribuyó el fracaso al desconocimiento y desconfianza por parte de promotores y desarrolladores, a la incapacidad de la demanda por acceder a la cuota inicial y cumplir con los requisitos de los ahorros, a la debilidad financiera de las empresas promotoras, a la reticencia y desconfianza de instituciones financieras grandes, a la demora en trámites municipales de habilitaciones urbanas y licencias, y a la cultura de informalidad (desconfianza) de la población (Ministerio de Vivienda, Construcción y Saneamiento [Mvcs], 2006). La consultora Stipe/ Viator (2007) sostuvo que el Ministerio de Vivienda tenía pocos años de formación (2002) y que el Programa Techo Propio estaba a cargo de su "natural" competidor: el Fondo Mivivienda. Este Fondo lograba una mayor rentabilidad de operaciones por medio del Nuevo Crédito Mivivienda, y no así con Techo Propio (p. 70).

La segunda etapa, enmarcada en el boom de la construcción, empezó cuando una gran empresa (IVC Contratistas Generales) desarrolló el proyecto "Las Casuarinas" en Ica, ofertando 1.500 unidades $^{6}$. Entre 2006 y 2012 se otorgaron 24.188 bonos, debido a una serie de arreglos institucionales que movieron la oferta "hacia arriba", al elevar los rangos del monto del valor de la vivienda de 4.000 - 8.000 dólares a aproximadamente 6.700 - 14.700 dólares americanos, eliminar el requisito del crédito a las familias (permitiéndoles recurrir a ahorros propios) y bajar los requisitos de ahorro mínimo exigido (el cual pasó de us\$ 950 en 2006 al 10\% del valor de la vivienda en 2008 y, en abril de 2009, al 3\% del valor de la vivienda) (SASE Consultores, 2010, p. 66).

Finalmente, la modalidad Adquisición de Vivienda Nueva se fue localizando en provincias. El departamento de Ica, entre agosto de 2006 y noviembre de 2012, captó casi el 30\% de los bonos; y el de La Libertad, el 22\%. Los resultados muestran que la mayor oferta no responde a la existencia de una mayor demanda efectiva. De esta manera, Trujillo, con 16.189 hogares como demanda efectiva, tuvo entre 2010 y 2011 unos nueve proyectos; y Lima, con su gran demanda efectiva, solo tuvo tres.

CuAdro 2 Localización del Bono Familiar Habitacional del Programa Techo Propio (agosto 2006-noviembre 2012)

\begin{tabular}{|c|c|c|c|c|c|c|}
\hline REGIÓN & AVN & $\%$ & CSP & MV & TOTAL & $\%$ \\
\hline Ica & 7.619 & 29,8 & 24.765 & 437 & 32.821 & 37,3 \\
\hline La Libertad & 5.644 & 22,1 & 8.736 & 68 & 14.448 & 16,4 \\
\hline Lima Metropolitana & 3.969 & 15,5 & 9.237 & 2.99 & 16.196 & 18,4 \\
\hline Arequipa & 1.719 & 6,7 & 371 & 2 & 2.092 & 2,3 \\
\hline Piura & 1.438 & 5,6 & 3.966 & 39 & 5.443 & 6,1 \\
\hline Lambayeque & 1.051 & 4,1 & 1.79 & 36 & 2.877 & 3,2 \\
\hline San Martín & 880 & 3,4 & 4.856 & 344 & 6.08 & 6,9 \\
\hline Otros & 3.169 & 12,4 & 3.354 & 95 & 6782 & 7,7 \\
\hline Total & 25.489 & 100 & 58.299 & 4.005 & 87.793 & \\
\hline
\end{tabular}

AVN = ADQUISICIÓN DE VIVIENDA NUEVA; CSP = CONSTRUCCIÓN EN SITIO PROPIO; MV = FONDO MIVIVIENDA. FUENTE MINISTERIO DE VIVIENDA, CONSTRUCCIÓN Y SANEAMIENTO (MVCS), HTTP://WWW.MIVIVIENDA. COM.PE/PORTALWEB/

6 Entrevista personal a Rodolfo Santa María, gerente de Proyectos Inmobiliarios en Fondo Mivivienda S.A. 


\section{Estrategias de rentabilidad}

La localización de Adquisición de Vivienda Nueva en provincias, y su escaso desarrollo en Lima, siendo parecidas las características de las viviendas, los costos de construcción y las condiciones de las familias, son factores que los constructores y promotores explican en función de los precios del suelo urbano.

Según el modelo de negocios en que operan los promotores y constructores, una manera simple de estudiar los precios de demanda es partir del cálculo económico. El "cálculo hacia atrás" empieza cuando los promotores conciben un programa de vivienda determinando la cantidad de terreno que necesitan, el tipo de producto inmobiliario que se construirá, el número de viviendas, las reservas de equipamientos, etcétera. Luego, observan en el mercado los precios que van a poder cobrar. A continuación, el promotor deduce los costos de construcción de los edificios sobre un terreno ya acondicionado y define la ganancia media de su intervención. Lo que queda es lo que pueden repartirse entre el promotor y el propietario del suelo: la sobreganancia localizada, la renta del suelo. Por tanto, no es la renta del suelo lo que determina el precio de la vivienda, sino el precio de esta lo que determina la renta (Topalov, 1979, pp. 166-170), capitalizando las externalidades relacionadas con el suelo (localización, servicios). El pago del constructor al propietario de tierras estará sujeto a la expectativa de la obtención de la ganancia de la operación inmobiliaria, aunque esto no impide que entre ambos agentes se produzca una negociación.

Debido a que el pago por la tierra (renta) está ligado al precio de la vivienda, conviene ubicar las expectativas de ganancia del constructor o promotor al interior de los diversos submercados de vivienda que demandan suelo. De manera simplificada, estos podrían reducirse a tres: i) el emprendimiento privado, que en principio no tiene un tope de precio; ii) la opción por la vivienda subsidiada para clase media, con un tope entre 14 UIT y 70 UIT (al cambio actual, de us\$19.950 y us\$99.750; y iii) la opción por la vivienda subsidiada para sectores de menores ingresos, con un tope de hasta 14 UIT (us\$19.949).

Se asume que el escenario sobre el cual el constructor o promotor decide los emprendimientos es el conjunto de los terrenos de la ciudad en que, para simplificar, operan todos los submercados. Aunque todos ellos hipotéticamente optaran por el emprendimiento privado, resulta claro que la limitación sería la reducida demanda efectiva de clase media alta y alta. Es aquí donde cabe ubicar la intervención subsidiaria del Estado que dirige créditos hipotecarios a la clase media (nivel B) y los bonos de Vivienda Nueva a la clase media emergente (nivel C). Con un añadido: en tanto mayor el tope de la vivienda por edificar, y mayor el monto del crédito hipotecario o bono, habrá más posibilidades de rentabilidad para el constructor y el promotor, y mayor posibilidad de que el propietario de tierras obtenga una mayor tajada en la negociación.

Los números muestran que los promotores y constructores han encontrado mayor rentabilidad en el producto para la clase media y, de hecho, para el Fondo Mivivienda este es su producto más rentable (Stipe/Viator, 2007). Al hecho de que Nuevo Crédito Mivivienda tenga mayores topes de precios, que en el año 2013 subieron de 50 a 70 UIT, se ańade la existencia de una clase media en ascenso que ha generado una mayor demanda interna por vivienda, entre otros bienes (por 
ejemplo, automóviles, cuya venta se incrementó en 2012 respecto de ańos anteriores). La posibilidad de ofertar viviendas a mayor precio, y con el crédito hipotecario subsidiado, hace que los constructores se inclinen hacia esta demanda de clase media. Ello condiciona que los terrenos de mayor valor ubicados en Lima y áreas centrales de ciudades de provincias y, por tanto, mejor localizados, se destinen a la clase media.

La modalidad Adquisición de Vivienda Nueva tiene poca oferta en Lima, a pesar de la demanda. De alrededor de 68.000 bonos familiares, el $85 \%$ se ha otorgado en provincias. En Vivienda Nueva, el constructor o promotor se está dirigiendo a un precio final de la vivienda de alrededor de 12 UIT (unos us\$17.100), y no al de 12-14 UIT, debido al peso que representan los bonos para la demanda, un $42 \%$ del valor (Cuadro 3). El Estado paga casi la mitad del costo del inmueble y, por medio de los bancos, otorga un crédito de us\$ 8.208 contra la hipoteca de la vivienda $(48 \%)$. Los constructores y promotores no se dirigen al más bajo valor de la vivienda social (5,5 UIT), porque no les es rentable, algo que -según ha demostrado la experiencia- solo se ha conseguido al costo financiero y de suelo urbano del sector público.

\section{CUADro 3 | Esquema de financiamiento para Adquisición de Vivienda Nueva}

\begin{tabular}{|c|c|c|c|c|}
\hline \multirow{2}{*}{ CONCEPTO } & \multicolumn{2}{|c|}{ VALOR DE VIVIENDA I 2 UIT } & \multicolumn{2}{|c|}{ VALOR DE VIVIENDA I 4 UIT } \\
\hline & Us\$ & $\%$ & US\$ & $\%$ \\
\hline $10 \%$ cuota inicial & 1.710 & 10 & 1.995 & 10 \\
\hline $\mathrm{BFH}$ & 7.125 & 42 & 4.275 & 21 \\
\hline Préstamo hipotecario & $7.552,50$ & 48 & 13.680 & 69 \\
\hline Valor de la vivienda & 17.100 & 100 & 19.950 & 100 \\
\hline
\end{tabular}

NOTA PARA VIVIENDAS DE I 2 UIT, EL BFH ES DE 5 UIT; Y PARA VIVIENDAS DE I 4 UIT, EL BFH ES DE 3 UIT.

FUENTE MINISTERIO DE VIVIENDA, CONSTRUCCIÓN Y SANEAMIENTO (MVCS), HTTP://WWW.MIVIVIENDA. COM.PE/PORTALWEB/. ELABORACIÓN DE JULIO CALDERÓN.

Las condiciones en que opera la modalidad Vivienda Nueva permiten al promotor un pago por el suelo urbano de hasta us $\$ 50 / \mathrm{m}^{2}$; no es posible obtener rentabilidad con un pago mayor, en cuyo caso puede pensarse en las opciones para la clase media. En la revisión de los diarios de Lima y Trujillo, en Lima no se pudo encontrar en la periferia ofertas de terrenos que cumplieran ese requisito. Landaure (2010, p. ii), sobre el análisis de ocho proyectos Vivienda Nueva en Lima, concluye que tres de ellos no fueron rentables y dos a causa del precio de la tierra. En cambio, en Trujillo había terrenos en El Milagro a us $\$ 35 / \mathrm{m}^{2}$ o en Moche a us $\$ 22 / \mathrm{m}^{2}$, los que sí calificarían para emprendimientos Vivienda Nueva. Funcionarios de Vivienda de Trujillo declararon que en el cono norte de dicha ciudad había terrenos de us\$ 50/ $\mathrm{m}^{2}$; y en el cono sur (Moche, Delicias), de us\$30/ $\mathrm{m}^{2}$.

En una perspectiva diacrónica, el boom de la construcción desde 2006 ha incrementado el costo del suelo en Lima y ha afectado a los proyectos de la modalidad Adquisición de Vivienda Nueva. Del estudio de Landaure (2010) se extrae que en un proyecto registrado el 2002, Campoy, el costo del suelo servido representó el 6\% 
del costo total; en otro de 2004, el proyecto Santa Rita, tuvo un costo de $8,1 \%$; y, finalmente, en uno de 2008, Los Parques de El Agustino, alcanzó un 19,2\% del total. Actualmente, los constructores entrevistados estiman que el peso del costo de suelo asciende a entre $25 \%$ y $30 \%$ del costo total. Como habría ocurrido en Chile (Brian \& Sabatini, 2006), el incremento del precio del suelo carcome el subsidio a la vivienda social.

La casi nula oferta en Lima del Programa Techo Propio en su variante Adquisición de Vivienda Nueva contrasta con el hecho de que la edificación de viviendas en esta ciudad va en ascenso. Pese a que entre 2006 y 2011 el precio del suelo se ha multiplicado por cuatro, revelando una mayor participación del propietario de tierras en el negocio, la venta de viviendas no se ha frenado y, por el contrario, entre agosto de 2010 y julio de 2011 se ha disparado en un 47\% (CAPECO, 2011; Abecasis, 2011). En 2012 se ha llegado a una oferta formal de 22.000 viviendas, lo cual se considera un hito, aunque a precios por encima de los us\$ 50.000. En distritos de la periferia, en los que supuestamente podría funcionar Vivienda Nueva, hay departamentos en venta con precios de entre 45.000 y 54.000 dólares que tienen demanda, y ante los cuales Vivienda Nueva (con un precio dirigido a los 17.000 dólares) no puede competir por el suelo.

El incremento del precio del suelo urbano, y su secuela de escasez de terrenos para la vivienda social y la falta de rentabilidad de Vivienda Nueva en Lima, no expresa solo la mayor participación de los propietarios de la tierra por medio de la renta. Expresa fenómenos mayores, como el crecimiento económico, el boom de la construcción, el aumento de la clase media y su demanda por vivienda, los mayores subsidios públicos a la clase media y las estrategias de rentabilidad de constructores y promotores. Es el precio de la vivienda lo que explica la renta del suelo, y no a la inversa. Los agentes económicos (constructores y propietarios de tierras) optarán por el Nuevo Crédito Mivivienda (clase media), porque el mayor subsidio y demanda efectiva permiten mayores ganancias y rentas. Por eso, el 76\% de la inversión de este programa se desarrolla en Lima, donde, a la vez, no existen terrenos para la vivienda social de los sectores de menores ingresos.

Aunque Vivienda Nueva tiene mayor desarrollo en provincias, conviene no ser tan optimistas frente al futuro, debido a que, entre otras cosas, el crecimiento económico está llegando. Vivienda Nueva se desarrolla en provincias porque el precio del suelo es menor y hay, hasta ahora, terrenos para vivienda social, aunque se perciben dificultades para la rentabilidad de la operación. Siendo así, algunos constructores estiman que hay problemas de rentabilidad y que, en algunos casos, solo se pueden conseguir terrenos muy alejados sobre los que no hay demanda y hacia los cuales es difícil instalar servicios definitivos (vías, electricidad, agua), lo que genera soluciones provisionales.

Las intervenciones en torno al espacio construido constituyen otro ámbito en que se ponen en práctica las estrategias de rentabilidad de los constructores y promotores. Se opta por la vivienda unifamiliar antes que por el edificio multifamiliar. De 104 proyectos Vivienda Nueva registrados al 2011, solo siete (6,7\%) eran del tipo multifamiliar, y cuatro de ellos se ubicaban en Lima (Orihuela, 2011,pp.16-25) ${ }^{7}$.

7 En Lima se trata de Campoy, Santa Rita, La Muralla y Los Parques de El Agustino. Además, García Ronceros en Arequipa, Talara en Piura y Las Brisas I Etapa en Huánuco. 
Según funcionarios del Fondo Mivivienda, la construcción de un departamento desborda el valor de las 12 UIT, dado que se encarece a medida que aumenta el número de niveles y, además, no existe el derecho del promotor a combinar usos. La construcción por etapas ha sido otra estrategia implementada. Debido a que las normas establecen la reserva de áreas para parques (8\%) y educación (2\%), en la lógica del constructor se "pierde" un $10 \%$ del terreno adquirido, lo que se enfrenta por medio de la estrategia de comprar un terreno de unas cuatro hectáreas y ejecutar la obra en cuatro o cinco etapas. Por lo común, el parque se deja para la última etapa, en tanto que el empresario busca recuperar el capital invertido. Por último, se ejecutan los programas de vivienda mixtos, que combinan más de un programa público, los dirigidos a la clase media y Vivienda Nueva (Landaure, 2010).

\section{Aspectos financieros}

A las Instituciones Financieras Intermediarias (IFI) no les ha resultado "atractiva" la colocación de los créditos hipotecarios de Adquisición de Vivienda Nueva. Estas entidades administran los fondos (bonos, ahorros y créditos), evalúan los proyectos presentados por los constructores, exigiéndoles sobre todo "fianzas solidarias" (antes que Carta Fianza o fideicomiso), controlan y supervisan los desembolsos de acuerdo con el avance de la obra. Se han limitado a utilizar los recursos proporcionados por el Estado, sin involucrar los propios, a pesar del spread ${ }^{8}$ que obtienen: reciben fondos a una tasa de interés del 6,6\% y los colocan al usuario a $10 \%$ o $12 \%$.

Para las financieras, la modalidad Vivienda Nueva es un producto secundario. Los montos absolutos no les representan ingresos importantes, temen no obtener rentabilidad y trabajar a pérdida. Para los bancos, los costos de transacción de un crédito hipotecario no se diferencian por monto de crédito otorgado. El crédito hipotecario en Vivienda Nueva es un monto bajo, especialmente. Siendo que el promedio de los precios de las viviendas es us\$17.100, el subsidio (bono) de us\$7.125 y el ahorro del beneficiario de us\$1.710, el crédito hipotecario asciende solamente a us\$7.552,5. El Nuevo Crédito Mivivienda para clase media sí resulta atractivo a las financieras, y el promedio del valor de los créditos hipotecarios en general, a abril 2012, bordeaba los us\$82.000 (Diario Gestión, 17/04/12).

\section{La intervención pública}

El mercado de la vivienda es producto de un doble movimiento, en que el Estado construye la demanda por medio de la propiedad y de la asignación de los recursos mediante leyes y reglamentos, y construye la oferta por medio de la política en materia de crédito a los constructores (Bourdieu, 2002, p. 32). El aporte estatal es sustancial, por definición, en el caso de la vivienda social. Vivienda Nueva opera por medio de una banca de segundo piso, la cual provee crédito (hipotecario) a la banca privada para el financiamiento y entrega de bonos habitacionales a la demanda; expide leyes y reglamentos que definen el producto inmobiliario y las condiciones de la propiedad, licita y habilita tierra urbana para reducir costos, entre otros. 
A pesar de la amplitud de la intervención estatal, la agenda pública establecida con los agentes económicos clave se limita a la discusión sobre mayores bonos y subsidios y dotación de tierra pública barata. Por ejemplo, la Cámara Peruana de la Construcción (CAPECO) insiste en el aumento de los subsidios sosteniendo que:

Se necesita construir 120.000 viviendas al año para cubrir la demanda actual, y ello solo será posible si se mantiene una tasa de inflación baja como condición básica para que el sistema bancario siga ofreciendo créditos hipotecarios a largo plazo. Una segunda condición es que el Estado continúe ofreciendo subsidios para la compra de la vivienda a las familias de menores ingresos (...). El Estado presupuesta us\$ 130 millones por año para financiar estos subsidios y tendría que aumentar ese valor al triple... (Piazza, 2011 p. 18)

El modo de enfrentar el problema del suelo para la vivienda social se ha visto restringido al pedido de provisión de tierra pública barata. En el ańo 2003, el Programa de Apoyo al Sector Habitacional (PASH) desarrolló el componente Producción Urbana Primaria (PUP), demostrativo y de intervención limitada. El componente preveía el desarrollo de los predios hasta el nivel de macrolotes, para licitación en venta posterior a los inversionistas privados. A pesar de los esfuerzos normativos ${ }^{9}$ fue un fracaso. Posteriormente, el Estado procedió a licitar tierra pública en Lima ${ }^{10}$. En enero de 2012 se creó el Programa Suelo Urbano (D.S. 003-2012-Vivienda). En abril de 2012, el propio ministro de Vivienda expresó: "al haber escasos terrenos, los precios suben y ponen a las vivienda fuera del alcance de los más pobres. Eso significa que el Estado debe poner a disposición del mercado estos terrenos" (Diario Gestión, 11.06.12, p. 15).

La restricción del problema del suelo para la vivienda social a la oferta de tierra pública barata circunscribe el debate al modelo de política de vivienda puesto en práctica. Dicha opción deja fuera de agenda medidas de diverso tipo, como una reglamentación del uso del suelo que fije porcentajes para la vivienda social, urbanización asociada entre el Estado y actores privados o comunitarios, medidas contra la especulación del suelo por los propietarios, e instrumentos financieros como la participación en plusvalías, que permitan recuperar los incrementos en los precios del suelo producidos por la intervención pública (Maldonado, 2012, pp. 182-183). Se deja manos libres al comportamiento especulativo y patrimonial de los pequeños propietarios agrícolas, decisión con una clara connotación ideológica que asume la defensa irrestricta del derecho de propiedad.

Un segundo tema que amerita su inclusión en la agenda pública tiene que ver con la focalización de los proyectos Vivienda Nueva y la calidad de vida en los conjuntos residenciales. ¿Vivienda Nueva se está realmente dirigiendo a su público

9 En febrero de 2006, la Ley 28687 amplió en la consideración para la vivienda de interés social a los terrenos de propiedad privada o de comunidades campesinas de la costa. La ley encargó al Ministerio de Vivienda llevar adelante el Banco de Tierras (artículo 23).

10 En Los Parques de El Agustino, los terrenos del excuartel "La Pólvora" fueron vendidos a los constructores a us $\$ 14,97 / \mathrm{m}^{2}$, siendo su precio de mercado us $\$ 50 \mathrm{us} / \mathrm{m}^{2}$ (Lecca, 2011, p. ii). Los terrenos (640 hectáreas) del exaeródromo de Collique en Comas (Programa Sol de Collique) se habrían vendido a us $\$ 30 / \mathrm{m}^{2}$, siendo el precio de mercado unos us $\$ 200 / \mathrm{m}^{2}$. Véase Paco Moreno (La Primera del 25/07/2010, p. 9), "Negociazo en Collique" y Riofrío, (2010, pp. 77-83). 
objetivo? A pesar de que oficialmente se dirige a los niveles $\mathrm{C}$ y $\mathrm{D}$ de la demanda efectiva, en realidad hay una abierta predominancia del nivel $C$. El ingreso familiar mensual de los propietarios beneficiarios encuestados, a enero de 2012, era de 1.540 soles (unos us $\$ 570)^{11}$, superior al promedio del nivel socioeconómico $\mathrm{C}$ que, de acuerdo con las cifras del Ministerio de Vivienda, era de us\$ 450 al 2011. Un 41\% obtenía entre 250 y 500 dólares, ubicándose en el nivel C, mientras que un 37\% tenía como ingreso entre 501 y 750 dólares, mayor que el promedio del nivel C, pero sin alcanzar el promedio del nivel B (US\$ 925). Un 6\%, con ingresos mayores a us $\$ 1.000$, formaría parte del nivel B beneficiado por Vivienda Nueva y, lo que es más importante, solo un 5\% con ingresos hasta US\$250 encajaría entre el nivel D y el E. El 62\% de los propietarios eran trabajadores formales (afiliados al seguro social), en una ciudad como Lima, en que el empleo formal bordea el $45 \%$. Solo una minoría estaba compuesta de trabajadores por cuenta propia (18\%).

\section{Reflexión final}

El meollo de la discusión urbanística en América Latina y en el Perú es la producción de vivienda formal para contrarrestar la informalidad urbana. Ello implica asumir que las políticas de regularización y mejoramiento de asentamientos precarios han mostrado ya todos sus límites y consecuencias negativas para la ciudad y que, aunque continuarán existiendo para atender la demanda generada ( $y$, de paso, dando pie a prácticas clientelares por parte de las elites), conviene pensar en soluciones formales a las ciudades. Es esta la promesa explícita que plantea la vivienda social en América Latina.

Los resultados de este estudio muestran, en primer lugar, dificultades del conjunto de la política de vivienda social en el Perú. Sobre un déficit cuantitativo de 389.745 unidades al 2007, Nuevo Crédito Mivivienda ha apoyado la construcción de 67.167 viviendas; y Techo Propio Vivienda Nueva, a 30.591 viviendas, con lo cual se habría cubierto el 25,08\% del déficit. Sobre un déficit cualitativo de 1.470.947, entre Techo Propio Construcción en Sitio Propio y Mejoramiento de Vivienda se ha apoyado a 68.637 viviendas, esto es, 4,64\%. Los subsidios se han orientado a la clase media (niveles $\mathrm{B}$ y C) por medio de mayores bonos y montos. Los mayores montos han ido a atender la demanda cuantitativa, a pesar de que el Plan Nacional de Vivienda 2006-2015 plantea atender a la demanda mayoritaria, esto es, la cualitativa. Esto ha sido así porque, a la vez, la política de vivienda busca estimular la industria de la construcción y esta encuentra rentabilidad en la vivienda nueva para la clase media.

En segundo lugar, en el programa de vivienda social denominado Adquisición de Vivienda Nueva, el estudio encuentra que solo alcanzó el 30\% de sus metas fijadas, por dificultades de rentabilidad para configurar una oferta de vivienda social a los precios establecidos por las autoridades. Por lo tanto, la demanda de menores ingresos sigue orientándose por mecanismos informales. Según el Ministerio de

11 Debe indicarse que los propietarios ocuparon las viviendas hacia 2004-2006 y pudiera ser que al momento de la encuesta (enero de 2012) sus ingresos hubieran mejorado. 
Vivienda, en 2012, en el territorio nacional el número de barrios urbanos marginales era de 6.079. Por su parte, el número de proyectos de vivienda social nueva entre 2003 y 2011 solo fue de 104 proyectos.

En lo sustancial, estas limitaciones han obedecido al incremento de los precios del suelo urbano de las periferias de las ciudades.

Para el sector empresarial, un precio del suelo por fuera de los alcances de la vivienda social para los sectores de menores ingresos se resuelve con mayores subsidios y oferta de tierra pública barata. Para la elite empresarial y estatal, el problema son los altos precios por la tierra, y no el comportamiento de los propietarios de la tierra, como tales, dado que un recurso ideológico (de defensa irrestricta de la propiedad privada) separa el precio del suelo de los agentes económicos que lo generan. El razonamiento económico predominante de la política pública plantea, una vez más, que el Estado ubique un banco de tierras de su propiedad, lo urbanice y lo ofrezca barato a los promotores y constructores. Es muy probable, y la experiencia lo demuestra ${ }^{12}$, que estas medidas tengan poco efecto en realidad, dificultando los objetivos de integración y de inclusión social que animan la construcción de la vivienda social. La medida de su fracaso será la continuidad de las invasiones de tierras y los "cuartos" de alquiler: la ciudad informal e ilegal.

Este estudio, aunque desde un foco de análisis en los modelos de negocios y la disputa de sobreganancias localizadas (rentas), no deja de advertir la complejidad y multicausalidad de los problemas del programa Adquisición de Vivienda Nueva. La explicación del incremento del precio del suelo considera otros factores apenas mencionados, como el crecimiento de la economía, el boom de la construcción, el incremento de la clase media, la reducción de la pobreza y la configuración del mercado inmobiliario, aspectos -todos ellos- paradójicamente considerados positivos por el pensamiento oficial y lineal. Siendo así, el estudio apunta a indicar la desconexión entre los propósitos de una política pública (la vivienda social para la inclusión) y el comportamiento de los mercados inmobiliario y de suelo, cuya comprensión resulta oscurecida por el propio modelo de política puesto en práctica. Por tanto, resolver los problemas de Adquisición de Vivienda Nueva requiere trascender ese limitado modelo, que entrega las soluciones a la iniciativa privada y reduce el Estado a un rol facilitador.

El Estado debe tener un papel más activo en la producción de la vivienda social y no restringir su intervención al otorgamiento de subsidios y tierra urbana barata. El Estado debe, echando mano de otras experiencias en la región ${ }^{13}$, plantear un modelo alternativo en el que asuma mayor peso e iniciativa, a la vez que aproveche los mecanismos del mercado y las iniciativas empresariales de los agentes privados. Para este propósito, se debe empezar por reconocer los retos que implica

12 Ha habido experiencias puestas en práctica hace cinco o seis años que han mostrado que el suelo barato público solo en parte menor se destinó a vivienda social, mientras la nueva legislación contempla el uso de estas tierras también para "iniciativas privadas" que no necesariamente son vivienda social.

13 Aunque la política de vivienda en Colombia no se encuentra exenta de críticas, una experiencia de banco de tierras como Metrovivienda en Bogotá produjo en 2008 unas 18.400 viviendas de entre 12.000 y 17.500 dólares americanos (Maldonado, 2012, p. 196), un 60\% de todas las que AVN produjo en todo el Perú entre 2003 y 2012. 
la vivienda social: organizar financieramente los programas, incorporar el suelo a los usos requeridos por medio de los instrumentos de la planeación urbana, introducir servicios e infraestructura, organizar la demanda y contar con una administración pública eficaz.

En específico, y a partir de la utilización del recurso suelo aquí analizado, los programas de vivienda social nueva deben contemplar un proceso de urbanización asociada que vincule al sector público con los propietarios de tierras. La tarea es ubicar tierras, que en Perú bien pueden ser privadas, públicas o de las comunidades campesinas de la costa (esto último implicaría modificaciones legales), a las cuales el Estado debería dotar de infraestructura a cambio de reserva de áreas para vivienda social cedidas por los propietarios. Un planteamiento de esta índole reorientaría la inversión pública en infraestructura, no a modo de un fondo perdido, como ocurre cuando se limita a generar el capital fijo para el negocio empresarial, sino de manera de promover un crecimiento planificado de la ciudad y de vivienda decente para la gente. De este modo, la vivienda social cortaría el flujo perverso que sostiene la informalidad urbana, por el cual la tierra ofrecida ilegalmente es barata y se adecúa a la demanda precisamente porque no cumple con los requisitos urbanísticos y/o se localiza donde la tierra es no enajenable. En el marco de asociaciones público/ privadas, el Estado debe canalizar las inversiones de infraestructura hacia áreas planificadas para la expansión urbana.

El estudio ha constatado que entre constructores y funcionarios públicos hay un conocimiento adecuado y relativamente profundo de las propuestas alternativas al modelo vigente en el Perú. Algunos observan con buenos ojos dichas innovaciones (reserva para áreas de vivienda social, captura de plusvalías urbanas, ajuste de tierras). Es el momento para que Perú ensaye otras opciones que consideren un mayor subsidio en vivienda para los sectores de menores ingresos (hoy orientado hacia la clase media en tres veces más); declaratorias de desarrollo prioritario en zonas de expansión que combatan la especulación de propietarios patrimonialistas; mayor participación de las municipalidades en control y programas de vivienda y acceso al suelo; propuestas de gestión o urbanización asociada que incorporen al Estado, constructores y a las comunidades campesinas sobre las que se están expandiendo las ciudades de manera ilegal, entre otros. 


\section{Referencias bibliográficas}

Abecasis, R. (2011). El precio de los terrenos se cuadruplicó en solo 5 años en Lima. Perú21.PE, viernes 2 de diciembre de 2011. En http://peru21.pe/2011/12/02/economia/preciosterrenos-lima-se-cuadruplicaron-5-anos-2001472

Barragán, P. (2005). Magnitud de la economía informal en el Perú y en el mundo. En Gestión en el Tercer Milenio, Revista de Investigación de la Facultad de Ciencias Administrativas, 7(14), 43-51. En http://sisbib.unmsm.edu.pe/bibvirtualdata/publicaciones administracion/ N14_2005/a04.pdf

Bassett, K. \& Short, J. (1980). Housing and residential structure. Alternative Approaches. Londres, Boston y Henley: Routledge \& Kegan Paul.

Bourdieu, P. (2002). Las estructuras sociales de la economía. Buenos Aires: Manantial.

Brian, I. \& Sabatini. F. (2006). Los precios del suelo en alza carcomen el subsidio habitacional, contribuyendo al deterioro en la calidad y localización de la vivienda social. Prourbana, 4, 2-13. En http://bit.ly/1zdKv9d

Calderón, J. (2006). Mercado de tierras urbanas, propiedad y pobreza. Lima: Lincoln Institute of Land Policy / SINCO Editores.

Calderón, J. (2009). El efecto Mivivienda: política de vivienda para la clase media y diferenciación social. En Ecuador Debate, La cuestión de la vivienda hoy, 76, 107-122. En http://flacsoandes.org/dspace/handle/10469/4186

Calderón, J. (2012). Las políticas de vivienda social: entre la vivienda nueva y la construcción en sitio propio. Revista de Sociología, 22 (Universidad Nacional Mayor de San Marcos, Lima).

Cámara Peruana de la Construcción (CAPECO). (2011). XVI Estudio "El mercado de edificaciones urbanas de Lima Metropolitana y el Callao". Lima: CAPECO.

Cortés, L. (1995). La cuestión residencial. Bases para una sociología del habitar. Madrid: Fundamentos.

Eyzaguirre, H. \& Calderón, C. (2003). El mercado de crédito hipotecario en el Perú. Lima: Instituto Apoyo/Banco Interamericano de Desarrollo (вІD).

Fondo Mivivienda. (2006). Estudio de mercado de la vivienda social en la ciudad de Lima. Lima: Fondo Mivivienda.

Fondo Mivivienda. (2009). Estudio de mercado de la vivienda social en la ciudad de Trujillo. Lima: Fondo Mivivienda. En http://bit.ly/TUgvP6

Hidalgo, R. (2007). ¿¿Se acabó el suelo en la gran ciudad? Las nuevas periferias metropolitanas de la vivienda social en Santiago de Chile. EURE, 33(98), 57-75. http://dx.doi. org/10.4067/S0250-71612007000100004

Instituto Peruano de Economía (IPE). (2013). La economía informal: algunas precisiones. Negocios Internacionales, 18. En http://www.comexperu.org.pe/media/files/revista/ febrero04\%5Canalisis.pdf

Iriarte, P. (2011). Limitaciones en el desarrollo de una oferta efectiva en el marco del Programa Techo Propio para proyectos habitacionales masivos bajo la modalidad de Adquisición de Vivienda Nueva (AVN) 2001-2011. Seminario de Vivienda de Interés Social. Lima: Universidad Nacional de Ingeniería (UNI). 
Jaramillo, S. (2012). Urbanización informal: diagnósticos y políticas. Una revisión al debate latinoamericano para pensar líneas de acción actuales. En C. Salazar (Coord.),I-regular: suelo y mercado en América Latina (pp. 33-83). México, D.F.: El Colegio de México.

Landaure, J. (2010). Influence of land value in the profitability of low income housing projects in periphery of Lima. Tesis, Master's programme in urban management and development. Institute for Housing and Urban Development Studies (IHS), of the School of Economics (ESE) and the Faculty of Social Sciences (FSS) of the Erasmus University, Rotterdam, The Netherlands / Lincoln Institute of Land Policy / Rotterdam City Development Corporation (OBR). En: thesis.eur.nl/pub/11566/(1)34675.pdf

Lecca, R. (2011a). Los parques de El Agustino. Una experiencia de integración social. Curso "Problema Nacional de la Vivienda". Lima: Universidad Nacional de Ingeniería (UNI).

Lecca, R. (2011b). El rol de los planes y programas de VIS promovidos por el Estado en la reconstrucción de viviendas. Seminario de Vivienda de Interés Social. Lima: Universidad Nacional de Ingeniería (UNI).

Maldonado, M. M. (2012). Limitaciones de las políticas de suelo y vivienda social para superar la exclusión social. La experiencia de Bogotá. En C. Salazar (Coord.), I-regular: suelo y mercado en América Latina (pp. 159-212) . México, D.F.: El Colegio de México.

Ministerio de Economía y Finanzas (MEF). (2011, mayo). Marco macroeconómico multianual 2012-2014. Lima: MEF. En http://bit.ly/1lFHHrg

Ministerio de Vivienda, Construcción y Saneamiento (mvcs). (2006). Plan Nacional de Vivienda 2006-2015, "Vivienda Para Todos". Lima: mvcs. En http://bit.ly/1oiCHvJ

Ministerio de Vivienda, Construcción y Saneamiento (Mvcs). (2007). Producción Urbana Primaria. Lima: Mvcs.

Ministerio de Vivienda, Construcción y Saneamiento (Mvcs). (2009). Resolución Ministerial 128-2009-VIVIENDA. Lima: mvcs. En http://bit.ly/1zdUXO3

Orihuela, J. (2011). Techo Propio: AVN Adquisición de Vivienda Nueva. Curso "Problema Nacional de la Vivienda”. Lima: Universidad Nacional de Ingeniería (UNI)

Piazza, W. (2011). Construcción: impulsor del crecimiento económico. En Links Japan Peru, No 9, mes de julio, Lima. En http://www.ccipj.org.pe/LINKSforWEB/no9july2011/ LINKS9\%20full.pdf

Pradilla, E. (1982). Ensayos sobre el problema de la vivienda en América Latina. México, D.F.: Universidad Autónoma Metropolitana, Unidad Xochimilco.

Ramos, D. (2010). La política habitacional en el Perú. Presentación realizada por el viceministro de Vivienda y Urbanismo en el evento La consolidación del sector vivienda, organizado por Uniapravi [Unión Interamericana para la Vivienda]. Lima, agosto.

Riofrío, G. (2010). Alan García. Alcalde de Lima En Perú Hoy. Desarrollo, democracia y otras fantasias. Lima: DESCO.

Richardson, H. (1975). Economía del urbanismo. Madrid: Alianza Universidad.

Rodríguez, A. \& Sugranyes, A. (2009). El traje del nuevo emperador: las políticas de financiamiento de vivienda social en Santiago de Chile. En A. Rodríguez \& P. Rodríguez (Eds.), Santiago, una ciudad neoliberal (pp. 301-325). Quito: Organización Latinoamericana y del Caribe de Centros Históricos (OLACCHI).

Sabatini, F. (1990). Precios del suelo y edificación de viviendas. EURE, 16(49), 63-72. http:// dx.doi.org/10.4067/S0250-71612000007700003 
Sase, Consultores. (2010). Evaluación de seguimiento técnico operativo al cuarto trimestre del año 2009, consolidado con los informes anteriores y evaluación comparativa respecto de los años 2008, 2007 y 2006. Informe final, elaborado por J. Calderón C. Lima: Sase, Consultores / Banco Interamericano de Desarrollo (BID) / Programa de Apoyo al Sector Habitacional (PASH). En http://www.vivienda.gob.pe/PASH/DOCUMENTOS/B_ INFORME_FINAL_STO_SASE.pdf

Segovia, O. (2006). Habitar en conjuntos de vivienda social: ¿cómo construir identidad, confianza y participación social? En A. Rodríguez \& A. Sugranyes (Eds.), Los con techo. Un desafio para la política de vivienda social (pp. 81-99). Santiago: Ediciones SUR.

Smolka, M. \& Sabatini, F. (2007). El debate sobre la liberalización del mercado de suelo en Chile. En M. Smolka y L. Mullahy, Perspectivas urbanas. Temas criticos en politicas de suelo en América Latina (pp. 278-283). Cambridge, MA: Lincoln Institute of Land Policy.

Stipe/Viator (Consultora Stipe S.p.A., Viator Proyectos S.A., Unión Transitoria de Empresas). (2007). Seguimiento Técnico Operativo del PASH - Fase I Informe No 6. Lima: Programa de Apoyo al Sector Habitacional (PASH).

Stockins, P. (2004). Oferta y demanda de vivienda en la periferia santiaguina: los nuevos desarrollos inmobiliarios. En G. Cáceres \& F. Sabatini (Eds.), Barrios cerrados en Santiago de Chile. Entre la exclusión y la integración residencial (pp. 83-111). Santiago: Lincoln Institute of Land Policy / Pontificia Universidad Católica de Chile.

Sugranyes, A. (2006). La política habitacional en Chile, 1980-2000: un éxito liberal para dar techo a los pobres. En A. Rodríguez \& A. Sugranyes (Eds.), Los con techo. Un desafío para la politica de vivienda social (pp. 25-59). Santiago: Ediciones SUR.

Topalov, Ch. (1979). La urbanización capitalista. México, D.F.: El Colegio de México.

Topalov, Ch. (1984). Ganancias y rentas urbanas. Elementos teóricos. Madrid: Siglo xxI.

Trivelli, P. (1994). Gestión del suelo urbano para la vivienda y el desarrollo de las ciudades. En Manejo del suelo urbano. Quito: Programa de Gestión Urbana (PGU) / Agencia Alemana de Cooperación Técnica (GTZ) / Lincoln Institute of Land Policy.

Trivelli, P. (2009). Sobre la evolución de la política urbana y la política de suelo en el Gran Santiago en el periodo 1979-2008. En A. Rodríguez \& P. Rodríguez (Eds.), Santiago, una ciudad neoliberal ((pp. 207-227). Quito: Organización Latinoamericana y del Caribe de Centros Históricos (OLACHI).

Trivelli, P. (2012). Boletín Mercado de suelo urbano, 121, tercer trimestre. Santiago: Autor. 